LAWRENCE LIVERMORE NATIONAL LABORATORY

\title{
Report on \\ Initial Direct Soil Leaching Experiments Using Post-Detonation Debris
}

R. Gostic, K. B. Knight, L. Borg

Lawrence Livermore National Laboratory

August 2011 


\section{Disclaimer}

This document was prepared as an account of work sponsored by an agency of the United States government. Neither the United States government nor Lawrence Livermore National Security, LLC, nor any of their employees makes any warranty, expressed or implied, or assumes any legal liability or responsibility for the accuracy, completeness, or usefulness of any information, apparatus, product, or process disclosed, or represents that its use would not infringe privately owned rights. Reference herein to any specific commercial product, process, or service by trade name, trademark, manufacturer, or otherwise does not necessarily constitute or imply its endorsement, recommendation, or favoring by the United States government or Lawrence Livermore National Security, LLC. The views and opinions of authors expressed herein do not necessarily state or reflect those of the United States government or Lawrence Livermore National Security, LLC, and shall not be used for advertising or product endorsement purposes.

\section{Auspices Statement}

This work performed under the auspices of the U.S. Department of Energy by Lawrence Livermore National Laboratory under Contract DE-AC52-07NA27344. 


\title{
Report on Initial Direct Soil Leaching Experiments Using Post-Detonation Debris
}

\author{
R. Gostic, K. B. Knight, L. Borg \\ Lawrence Livermore National Laboratory
}

\begin{abstract}
Introduction
A key challenge of nuclear forensics is reducing the time and manpower effort required to measure nuclear debris compositions. The overall motivation for this work is to explore development of a robust, automated system that can be used to concurrently analyze several elements/isotopes associated with the forensic signature of nuclear materials. The primary focus of this research has been to methodically investigate if rapid partial leaching of post-detonation debris can yield usable elemental and isotopic information for interpretation.
\end{abstract}

The unique requirements of post-detonation nuclear forensics have not been fully adapted to or fully incorporated contemporary chemical separation techniques. Challenges include addressing the range of material matrices or mixed fission product and actinide compositions and concentrations that might be encountered. These include, but are not limited to, puddle melt glass, urban debris, seawater, air filters, iron-rich urban debris, asphalt, and silica sand. Separation of these elements and their subsequent measurement is a key element of related laboratory analysis activity. Existing practices at LLNL rely on proven but time-consuming and labor intensive processes. Significant time and labor savings are possible in chemical separations, however, if rapid processing methods can be adapted to post-detonation debris.

Development of a simple and reliable leaching technique could shorten analytical times and would be useful as a field deployable method for the preliminary characterization of actinide isotopic ratios in soils. Measurement of isotopic ratios in the field using modern mass spectrometry capabilities such as Inductively Coupled Plasma Mass Spectrometry (ICP-MS) is desirable, taking advantage of the extended range of isotopic systems measureable using such instruments. Sample introduction to these types of mass spectrometry instruments requires partial leaching or full dissolution of a sample to remove isobaric (same mass) interferences, and, in some cases, to concentrate the elements(s) of interest. To develop a field-deployable mass spectrometry capability, therefore, automated and robust leaching of likely debris samples (ranging from silicates and oxides to metals and urban materials such as concrete and asphalt), followed by separation/purification through cation exchange column chemistry is necessary. In a post-detonation environment, analysis of melt glasses via rapid leaching and ICP-MS could be a viable route to the same goal.

This report presents initial leaching experiments on 'uncontaminated' soils, as well as data from melt glass from a single nuclear weapons test. Samples were characterized by gamma spectrometry, then aliquoted for rapid leaching experiments. Experiments were conducted using 
two different rapid acid treatments to leach the soils. Following leaching, the leachate solutions were analyzed by ICP-MS to determine if $\mathrm{U}$ isotopic composition. We present these data to address the question as to whether or not rapid ( $\sim \mathrm{hr})$ leaching techniques have the potential to yield meaningful $U$ isotopic compositions, without the need for a complete (time consuming) sample dissolution and separation.

\section{Experimental Methods}

Four surface soil samples were collected at the Nevada Test Site away from areas directly affected by weapons testing and fallout. Soils were analyzed by gamma spectroscopy to determine ${ }^{235} \mathrm{U}$ concentrations (Table 1). Two aliquots, $3 \mathrm{~g}$ each, were removed from each of these samples for sample leaching. The ${ }^{235} \mathrm{U}$ concentrations in each aliquot were extrapolated from the gross sample concentration. For each soil, one aliquot was then leached with $8 \mathrm{M} \mathrm{HNO}_{3}$ and the other aliquot was leached using a $2 \% \mathrm{HF}$ and concentrated $\mathrm{HNO}_{3}$ mixture. Both reagents were added to the aliquots at a ratio of $10 \mathrm{ml} / \mathrm{g}$ of sample at room temperature in polypropylene vials. Leach times were 1 hour at room temperature, with manual mixing. Following leaching, the acid solutions were separated from the solids by vacuum filtration using $0.1 \mathrm{um}$ pore size polypropylene filters. The $8 \mathrm{M} \mathrm{HNO}_{3}$ leachates were volumetrically diluted by a factor of 10 using a $5 \% \mathrm{HNO}_{3}$ solution containing a ${ }^{233} \mathrm{U}$ internal standard. The $2 \% \mathrm{HF}$ and concentrated $\mathrm{HNO}_{3}$ leachates were volumetrically diluted by a factor of 20 using a $5 \% \mathrm{HNO}_{3}$ solution containing the same ${ }^{233} \mathrm{U}$ internal standard.

\begin{tabular}{llll}
\hline Sample & Mass $(\mathrm{g})$ & $\begin{array}{l}\text { Estimated } \\
\text { (atoms/g) }\end{array}$ & $\begin{array}{l}\text { Estimated } \\
\text { (atoms/sample) }\end{array}$ \\
\hline Soil 22 -A & 3.0108 & $1.5 \mathrm{E}+14$ & $4.5 \mathrm{E}+14$ \\
Soil 22 -B & 3.0112 & $1.5 \mathrm{E}+14$ & $4.5 \mathrm{E}+14$ \\
Soil 46 -A & 3.0042 & $4.8 \mathrm{E}+13$ & $1.5 \mathrm{E}+14$ \\
Soil 46 -B & 3.0266 & $4.8 \mathrm{E}+13$ & $1.5 \mathrm{E}+14$ \\
Soil 50 -A & 3.0297 & $9.0 \mathrm{E}+13$ & $2.7 \mathrm{E}+14$ \\
Soil 50 -B & 2.9981 & $9.0 \mathrm{E}+13$ & $2.7 \mathrm{E}+14$ \\
Soil 64 -A & 3.0459 & $8.2 \mathrm{E}+13$ & $2.5 \mathrm{E}+14$ \\
Soil 64 -B & 3.0288 & $8.2 \mathrm{E}+13$ & $2.5 \mathrm{E}+14$ \\
Melt Glass - Solid & 0.499 & $2.6 \mathrm{E}+16$ & $1.3 \mathrm{E}+16$ \\
Melt Glass - Crushed & 0.4962 & $3.4 \mathrm{E}+16$ & $1.7 \mathrm{E}+16$ \\
Melt Glass - Powdered & 0.5667 & $2.5 \mathrm{E}+16$ & $1.4 \mathrm{E}+16$ \\
Reagent Grade $\mathrm{SiO}_{2}$-A & 3.018 & N/A & N/A \\
Reagent Grade $\mathrm{SiO}{ }_{2}$-B & 2.9931 & N/A & N/A \\
Reagent Blank -A & N/A & N/A & N/A \\
Reagent Blank -B & N/A & N/A & N/A \\
U005a Standard & N/A & N/A & N/A \\
\hline
\end{tabular}

Table 1: Sample masses and ${ }^{235} \mathrm{U}$ concentrations measured by gamma spectroscopy. The $\mathrm{A}$ and $\mathrm{B}$ samples represent duplicate measurements of the same sample. While absolute errors were not quantified, measurement reproducibility was excellent.

Three samples of melt glasses originating from a uranium-fueled surface test at the Nevada Test Site, from a nearby location to the 'uncontaminated' soils (and therefore having a similar soil composition/chemistry), were also selected for study. The melt glass aliquots each contained 0.5 $\mathrm{g}$ of glass, and were selected have a comparable grain size $(3.35 \mathrm{~mm})$ to the 'uncontaminated' soils. Preliminary ${ }^{235} \mathrm{U}$ concentrations of each melt glass sample was determined by gamma spectroscopy. The surface area of the melt glass samples was then altered for two of the three 
melt glass leaching experiments. One melt glass sample was powdered into a fine dust by grinding in a ball mill for two minutes using stainless steel grinding balls and an acrylic grinding vessel. The third sample was crushed into $0.5-2 \mathrm{~mm}$ grains by manually shaking the glass, using the same stainless steel balls and acrylic vessel used in the ball mill preparation, for 30 second. The third was left intact, with its original surface. The three melt glass samples [solid (3.35 mm), crushed $(0.5-2 \mathrm{~mm})$ and powdered (fine)] were then leached using similar procedures to those applied to the 'uncontaminated' soils. For each melt glass sample, one aliquot was leached with a $8 \mathrm{M} \mathrm{HNO}_{3}$ mixture. The reagents were added to the aliquots at a ratio of $10 \mathrm{ml} / \mathrm{g}$ of sample at room temperature in polypropylene vials. Leach times were 1 hour at room temperature, with manual mixing. Following leaching, the acid solutions were separated from the solids by vacuum filtration using $0.1 \mathrm{um}$ pore size polypropylene filters. The $8 \mathrm{M} \mathrm{HNO}_{3}$ leachates were volumetrically diluted by a factor of 10 , using a $5 \% \mathrm{HNO}_{3}$ solution containing the same ${ }^{233} \mathrm{U}$ internal standard. Only minimal dissolution of material was observed, and was confirmed by leachate analyses. Thus, the same samples were then used for $2 \% \mathrm{HF}$ with concentrated $\mathrm{HNO}_{3}$ leaching experiments, rather than introducing virgin material. The $2 \% \mathrm{HF}$ with concentrated $\mathrm{HNO}_{3}$ leachates were volumetrically diluted by a factor of 20 , using a $5 \% \mathrm{HNO}_{3}$ solution containing a ${ }^{233} \mathrm{U}$ internal standard. Table 1 contains the complete sample list.

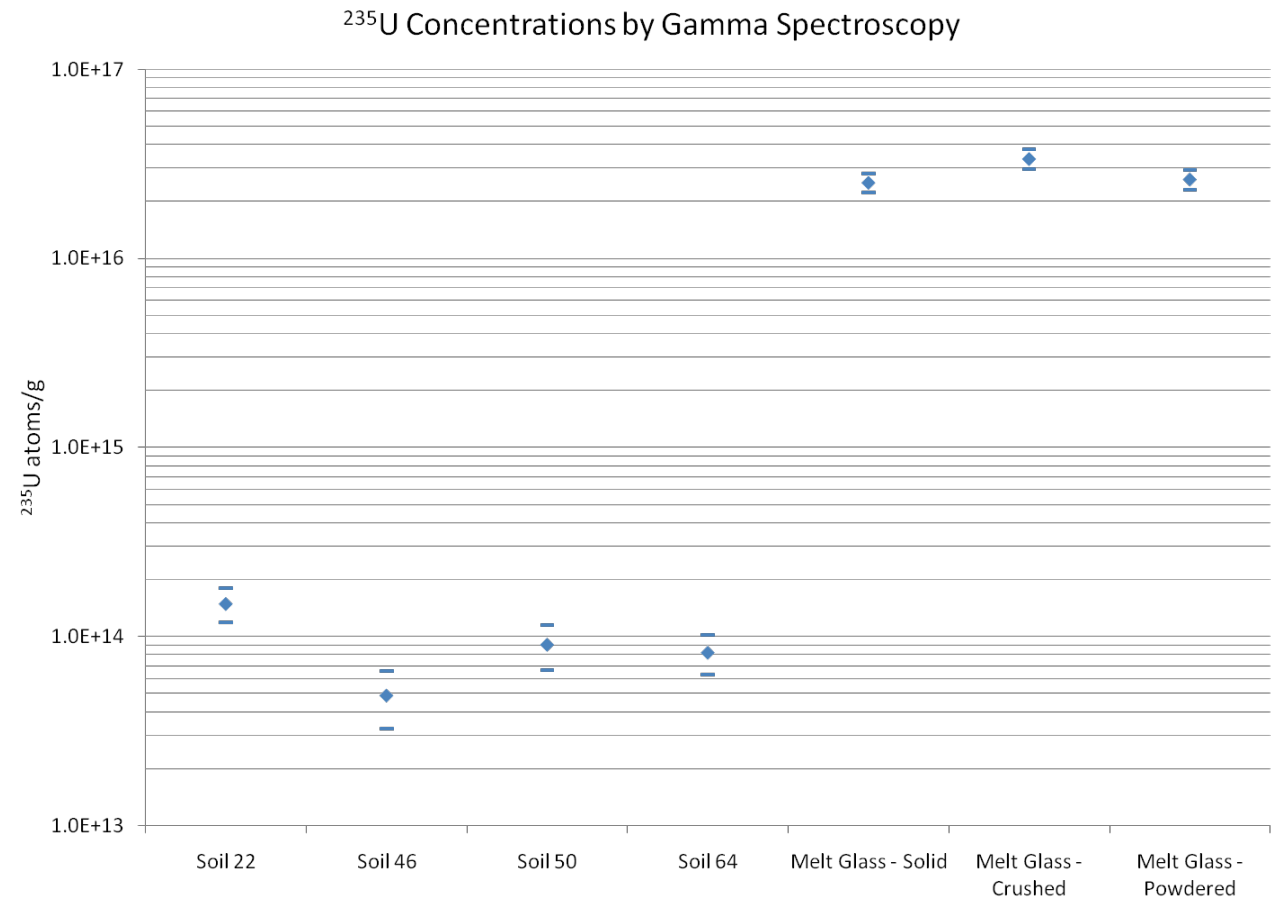

Figure 1: Semi-log plot of ${ }^{235} \mathrm{U}$ concentrations in the soil samples and melt glass samples determined by gamma spectroscopy. Soil concentrations are $\sim 10^{14}$ atoms $/ g$ of ${ }^{235} \mathrm{U}$, while melt glass concentrations are $\sim 10^{16}$ atoms/g of ${ }^{235} \mathrm{U}$. Errors are derived from the averages of the replicate analyses (1 standard deviation).

Collection of the ICP-MS data from the 11 samples ( 8 uncontaminated soil leachates and 3 melt glass leachates) was performed during a single experimental run using a Thermo X7 quadrupole ICP-MS instrument at LLNL. Analysis of reagent blanks was performed at the same time using two standards (the U005a standard, and a reagent grade $\mathrm{SiO}_{2}$ with an unknown U-isotopic composition, selected for improved matrix match). The standards leached using the same 
materials and methods as used in the soil samples. Data were acquired with peak jumping scans at masses 232 - 239 and 245 (background), and using a survey scan covering 5 - 259 AMU, for each sample. ICP-MS data for masses 235, 236 and 238 are presented in Table 2. As ICP-MS samples were prepared volumetrically, no absolute $U$ concentration values are reported, and uranium concentrations instead rely on initial gamma spectrometry analyses. Complete microwave dissolution of one soil sample and one melt glass sample were also done to obtain the full isotopic values of the samples for comparison with the leachates.

\section{Results and Discussion}

Gamma-spectrometry analyses yield ${ }^{235} \mathrm{U}$ concentrations on the order of $\sim 10^{14}$ atoms/g for all soil samples. The melt glasses, in comparison, yield concentrations two orders of magnitude greater $\left(\sim 10^{16}\right.$ atoms/g of ${ }^{235} \mathrm{U}$; see Table 1, Figure 1$)$.

Leaching of soil samples using the $2 \% \mathrm{HF}$ with concentrated $\mathrm{HNO}_{3}$ treatment, as well as the $8 \mathrm{M}$ $\mathrm{HNO}_{3}$ treatment, is effective at liberating enough $\mathrm{U}$ from the soil matrix to make statistically sound measurements of the ${ }^{238} \mathrm{U} /{ }^{235} \mathrm{U}$ of the samples by ICP-MS (Table 2). The measured ${ }^{238} \mathrm{U} /{ }^{235} \mathrm{U}$, however, varies with leach treatment and introduced sample form (solid, crushed and powdered).

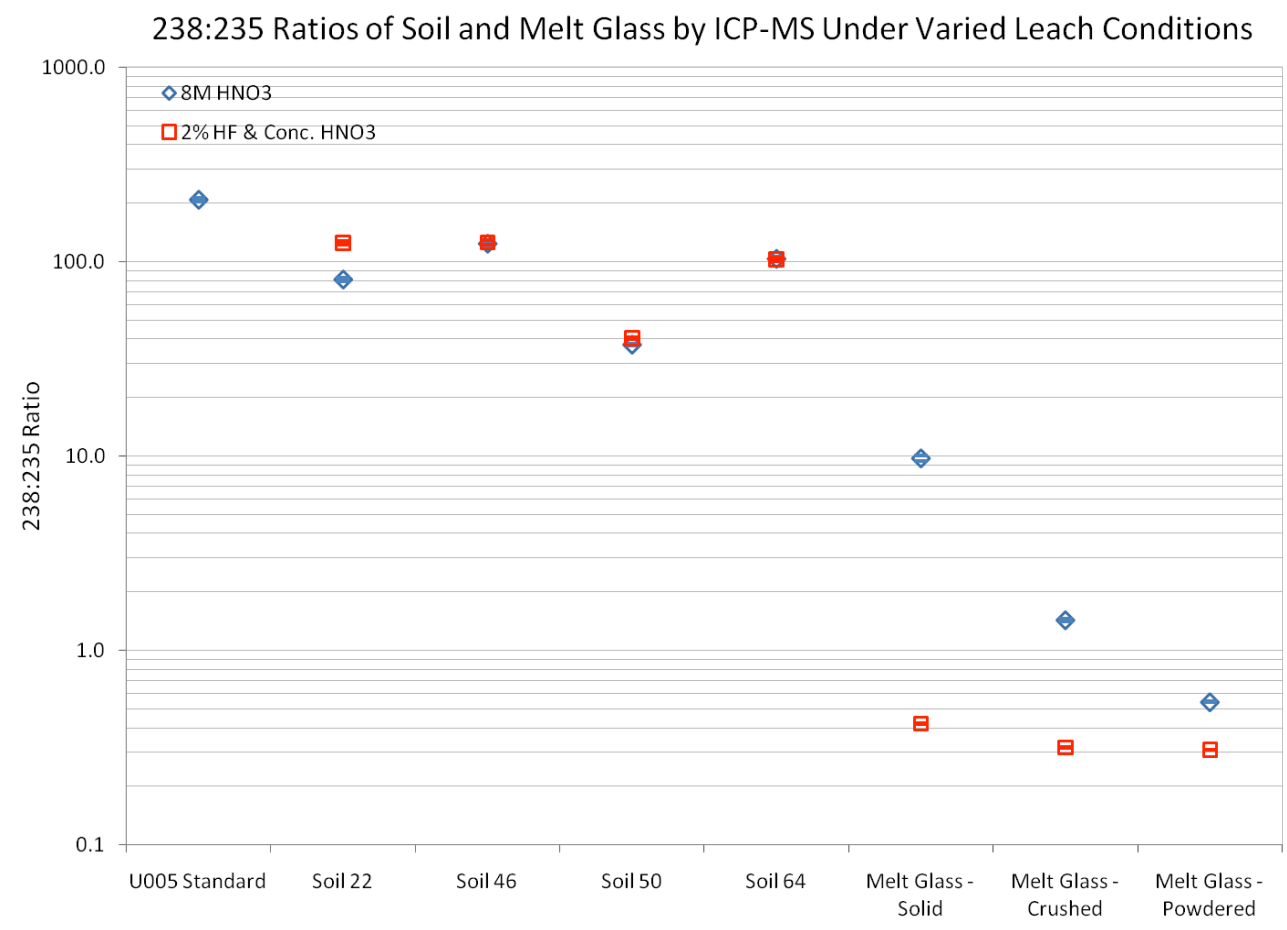

Figure 1: ${ }^{238} \mathrm{U} /{ }^{235} \mathrm{U}$ ratios for the $8 \mathrm{M} \mathrm{HNO} 3$ and the $2 \% \mathrm{HF}$ with concentrated $\mathrm{HNO}_{3}$ leaching experiments. The U005 standard has a reported ${ }^{238} \mathrm{U} /{ }^{235} \mathrm{U}$ value of 200 , the observed vale was $208 \pm 4$. Errors are generally within the symbols, and are $1 \sigma$.

The $2 \% \mathrm{HF}$ with concentrated $\mathrm{HNO}_{3}$ leachates from the soils contain $13-56 \%$ more $\mathrm{U}$ than the 8 $\mathrm{M} \mathrm{HNO}_{3}$ leachates (Table 2), resulting in the reduction of uncertainties for the $2 \% \mathrm{HF}$ with concentrated $\mathrm{HNO}_{3}$ system. The ${ }^{238} \mathrm{U} /{ }^{235} \mathrm{U}$ ratios (Figure 1) are reproducible within errors for both reagent systems in 3 of the 4 soil samples. Soil 22, when leached using the $2 \% \mathrm{HF}$ with 
concentrated $\mathrm{HNO}_{3}$ solution, yields an increased ${ }^{238} \mathrm{U}$ signal by $43 \%$, while the ${ }^{235} \mathrm{U}$ yield is increased by only $13 \%$, relative to the $8 \mathrm{M} \mathrm{HNO}_{3}$ leach, resulting in a fractionated isotopic ratio. It cannot be determined from these experiments whether this apparent isotopic fractionation is due to some introduced variation between aliquot $22-\mathrm{A}$ and $22-\mathrm{B}$, or if the $2 \% \mathrm{HF}$ with concentrated $\mathrm{HNO}_{3}$ solution is able to access a soil component rich in ${ }^{238} \mathrm{U}$ not leached by $8 \mathrm{M}$ $\mathrm{HNO}_{3}$, but present only in this soil.

\begin{tabular}{|c|c|c|c|c|c|c|c|c|}
\hline Sample & Leaching Reagent & $\begin{array}{l}\text { Counts } \\
\text { a } \quad 235 \\
\text { AMU } \\
\end{array}$ & $\begin{array}{l}\text { Counts } \\
\text { a } \quad 236 \\
\text { AMU } \\
\end{array}$ & $\begin{array}{l}\text { Counts } \\
\text { a } \quad 238 \\
\text { AMU } \\
\end{array}$ & ${ }^{236} \mathbf{U} \mathbf{U}$ & $\pm 1 \sigma$ & ${ }^{238} \mathbf{U} /$ & $\pm 1 \sigma$ \\
\hline Soil 22 -A & $8 \mathrm{M} \mathrm{HNO}_{3}$ & 1765 & 13 & 142827 & 0.0076 & 0.0021 & 80.9 & 1.9 \\
\hline Soil 22 -B & $2 \% \mathrm{HF}$, conc. $\mathrm{HNO}_{3}$ & 2032 & 3 & 254261 & 0.0013 & 0.0008 & 125 & 3 \\
\hline Soil 46 -A & $8 \mathrm{M} \mathrm{HNO}_{3}$ & 810 & 0 & 100164 & ${ }^{236}$ U n.d. & $N / A$ & 124 & 4 \\
\hline Soil 46 - B & $2 \% \mathrm{HF}$, conc. $\mathrm{HNO}_{3}$ & 1432 & 3 & 180350 & 0.0019 & 0.0011 & 126 & 3 \\
\hline Soil 50 -A & $8 \mathrm{M} \mathrm{HNO}_{3}$ & 5763 & 11 & 215535 & 0.0019 & 0.0006 & 37.4 & 0.5 \\
\hline Soil 50 -B & $2 \% \mathrm{HF}$, conc. $\mathrm{HNO}_{3}$ & 8319 & 15 & 336295 & 0.0018 & 0.0005 & 40.4 & 0.4 \\
\hline Soil 64 -A & $8 \mathrm{M} \mathrm{HNO}_{3}$ & 1349 & 2 & 139498 & 0.0015 & 0.0010 & 103 & 3 \\
\hline Soil 64 - B & $2 \% \mathrm{HF}$, conc. $\mathrm{HNO}_{3}$ & 3133 & 0 & 322446 & ${ }^{236}$ Un.d. & $N / A$ & 103 & 2 \\
\hline Soil - complete & $2 \% \mathrm{HF}$, conc. $\mathrm{HNO}_{3}$ & 4906 & 19 & 161175 & 0.0040 & 0.0010 & 32 & 8 \\
\hline $\begin{array}{l}\text { Melt } \\
\text { Solid }\end{array}$ & $8 \mathrm{M} \mathrm{HNO}_{3}$ & 1011 & 4 & 9847 & 0.0040 & 0.0020 & 9.74 & 0.32 \\
\hline $\begin{array}{l}\text { Melt Glass } \\
\text { Solid }\end{array}$ & $2 \% \mathrm{HF}$, conc. $\mathrm{HNO}_{3}$ & 194555 & 929 & 81553 & 0.0048 & 0.0002 & 0.419 & 0.002 \\
\hline $\begin{array}{l}\text { Melt Glass - } \\
\text { Crushed }\end{array}$ & $8 \mathrm{M} \mathrm{HNO}_{3}$ & 5516 & 24 & 7910 & 0.0044 & 0.0009 & 1.43 & 0.03 \\
\hline $\begin{array}{l}\text { Melt Glass - } \\
\text { Crushed }\end{array}$ & $2 \% \mathrm{HF}$, conc. $\mathrm{HNO}_{3}$ & 486343 & 2315 & 154245 & 0.0048 & 0.0001 & 0.317 & 0.001 \\
\hline $\begin{array}{l}\text { Melt Glass - } \\
\text { Powdered }\end{array}$ & $8 \mathrm{M} \mathrm{HNO}_{3}$ & 55247 & 293 & 29997 & 0.0053 & 0.0003 & 0.543 & 0.004 \\
\hline $\begin{array}{l}\text { Melt Glass } \\
\text { Powdered }\end{array}$ & $2 \% \mathrm{HF}$, conc. $\mathrm{HNO}_{3}$ & 836652 & 4000 & 258287 & 0.0048 & 0.0001 & 0.309 & 0.001 \\
\hline Glass - complete & $2 \% \mathrm{HF}$, conc. $\mathrm{HNO}_{3}$ & 862799 & 4300 & 169030 & 0.0050 & 0.0001 & 0.196 & 0.002 \\
\hline $\begin{array}{l}\text { Reagent } \quad \text { Grade } \\
\mathrm{SiO}_{2}-\mathrm{A}\end{array}$ & $8 \mathrm{M} \mathrm{HNO}_{3}$ & 11 & 0 & 1058 & ${ }^{236}$ Un.d. & $N / A$ & 95.6 & 28.9 \\
\hline $\begin{array}{ll}\text { Reagent } & \text { Grade } \\
\mathrm{SiO}_{2}-\mathrm{B} & \end{array}$ & $2 \% \mathrm{HF}$, conc. $\mathrm{HNO}_{3}$ & 37 & 1 & 3453 & 0.0365 & 0.0322 & 94.5 & 15.7 \\
\hline $\begin{array}{l}\text { Reagent } \\
\text { Blank -A }\end{array}$ & $8 \mathrm{M} \mathrm{HNO}_{3}$ & 7 & 0 & 797 & ${ }^{236}$ Un.d. & $N / A$ & 116 & 44 \\
\hline $\begin{array}{l}\text { Reagent } \\
\text { Blank -B }\end{array}$ & $2 \% \mathrm{HF}$, conc. $\mathrm{HNO}_{3}$ & 295 & 1 & 5568 & 0.0045 & 0.0039 & 18.9 & 1.1 \\
\hline $\begin{array}{l}\text { U005a } \\
\text { Standard }\end{array}$ & & 2235 & 19 & 464876 & 0.0084 & 0.0019 & 208.0 & 4.4 \\
\hline
\end{tabular}

Table 2: ICP-MS data for masses 235,236 and 238 by sample and reagent system. Errors are 1 $\sigma$. The certified values for $\mathrm{U} 005 \mathrm{a}$ are ${ }^{238} \mathrm{U} /{ }^{235} \mathrm{U}=196.46 \pm 0.12$ and ${ }^{236} \mathrm{U} /{ }^{235} \mathrm{U}=0.00233 \pm 0.00002$. 'Complete' samples indicate a complete microwave dissolution run by ICP-MS. 
Natural ${ }^{238} \mathrm{U} /{ }^{235} \mathrm{U}$ uranium isotopic ratios were not observed in any of the soils using these leaching treatments. Instead, all soils suggest some degree of ${ }^{235} \mathrm{U}$ enrichment. This may be a result of fractionation from the leaching process, but may also reflect the influence of contamination of the soils from weathering and transport of nuclear test debris with non-natural uranium isotopic composition at the Nevada Test Site. The U005a standard yielded a ${ }^{238} \mathrm{U}^{235} \mathrm{U}$ $208 \pm 4.4$, just outside of errors of the certified value. Both the ${ }^{238} U /{ }^{235} U$ and ${ }^{236} U /{ }^{235} U$ suggest some enhancement of the ${ }^{235} \mathrm{U}$ signal inconsistent with mass fractionation, but possibly reflecting a source of systematic error. Corrections were not made for potential hydride interferences. The leachate analyses of the homogeneous $\mathrm{SiO}_{2}$ standard yielded well-reproduced, non-natural ${ }^{238} \mathrm{U} /{ }^{235} \mathrm{U}$ compositions of $\sim 95$. While the true uranium isotopic composition of the $\mathrm{SiO}_{2}$ material is not known, the well-replicated precision confirms that the two reagent systems do not a prioi cause or introduce fractionation of uranium isotopes in silicate-dominated systems.

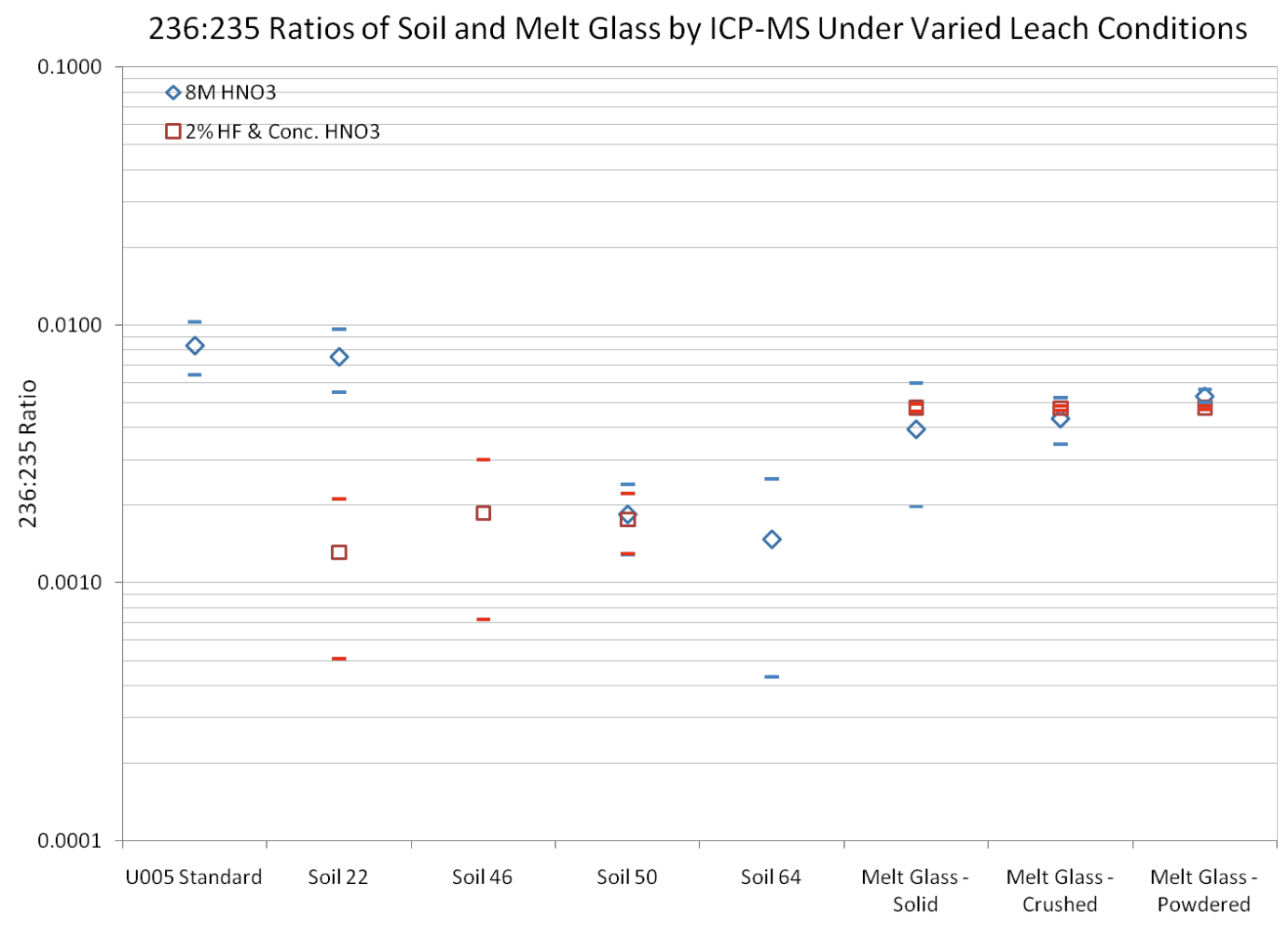

Figure 2: Melt glass samples yield a uniform ${ }^{236} \mathrm{U} /{ }^{235} \mathrm{U}$ ratio within errors regardless of the surface area of the leached sample. The large uncertainties in the ${ }^{236} \mathrm{U} /{ }^{235} \mathrm{U}$ ratios in the soils are due to small ${ }^{236} \mathrm{U}$ signals in the soils and from the $8 \mathrm{M} \mathrm{HNO}_{3}$ leached melt glass samples.

Unlike the soil samples, large variations are observed in the measured melt glass ${ }^{238} \mathrm{U} /{ }^{235} \mathrm{U}$ ratios across both reagent systems, and as a function of the physical form of the introduced sample (solid, crushed and powdered, see Figure 1). A decreasing ${ }^{238} \mathrm{U} /{ }^{235} \mathrm{U}$ ratio is observed in the $8 \mathrm{M}$ $\mathrm{HNO}_{3}$ leaching experiments as a function of increased surface area of the melt glass samples. Such a trend is highly suggestive of a bimodal mixing with surfacial natural-composition uranium dominating the most easily leached sites within the sample. The observed trends imply that the ${ }^{235} \mathrm{U}$ fuel component preserved the melt glass is not the dominant component being leached from the melt glass over these time scales and/or acid temperatures. 
The same trend of decreasing measured ${ }^{238} \mathrm{U} /{ }^{235} \mathrm{U}$ ratios is observed in the $2 \% \mathrm{HF}$ with concentrated $\mathrm{HNO}_{3}$ data, although the effect is not as dramatic as that observed with the $8 \mathrm{M}$ $\mathrm{HNO}_{3}$ system. In the case of the $2 \% \mathrm{HF}$ with concentrated $\mathrm{HNO}_{3}$ treatment, the crushed melt glass and powdered melt glass yield identical, minimum ${ }^{238} \mathrm{U} /{ }^{235} \mathrm{U}$ ratios within errors, and significantly lower that the ratio realized from the powdered melt glass $8 \mathrm{M} \mathrm{HNO}$ experiment. Both reagent systems demonstrate that increasing the surface area of the melt glass will provide a better representation of the gross ${ }^{238} \mathrm{U}^{235} \mathrm{U}$ ratio. The observed trends with increased surface area likely reflect a decreasing contribution from a background of natural isotopic composition $U$. The $2 \% \mathrm{HF}$ with concentrated $\mathrm{HNO}_{3}$ data, however, suggest that the primary ${ }^{238} \mathrm{U} /{ }^{235} \mathrm{U}$ component has been accessed, and that the background contribution from surfacial natural uranium has been minimized.

The ${ }^{236} \mathrm{U}^{235} \mathrm{U}$ isotopic ratios are plotted by sample in Figure 2. Precise determination of the ${ }^{236} \mathrm{U} /{ }^{235} \mathrm{U}$ ratio in the soil samples using either reagent system is difficult due to the low to absent ${ }^{236} \mathrm{U}$ concentration in the soil samples. This is not the case for the ${ }^{236} \mathrm{U} /{ }^{235} \mathrm{U}$ ratios in the melt glass samples, where the both the $8 \mathrm{M} \mathrm{HNO}_{3}$ and the $2 \% \mathrm{HF}$ with concentrated $\mathrm{HNO}_{3}$ leaching experiments yield measurable ${ }^{236} \mathrm{U}$ signals.

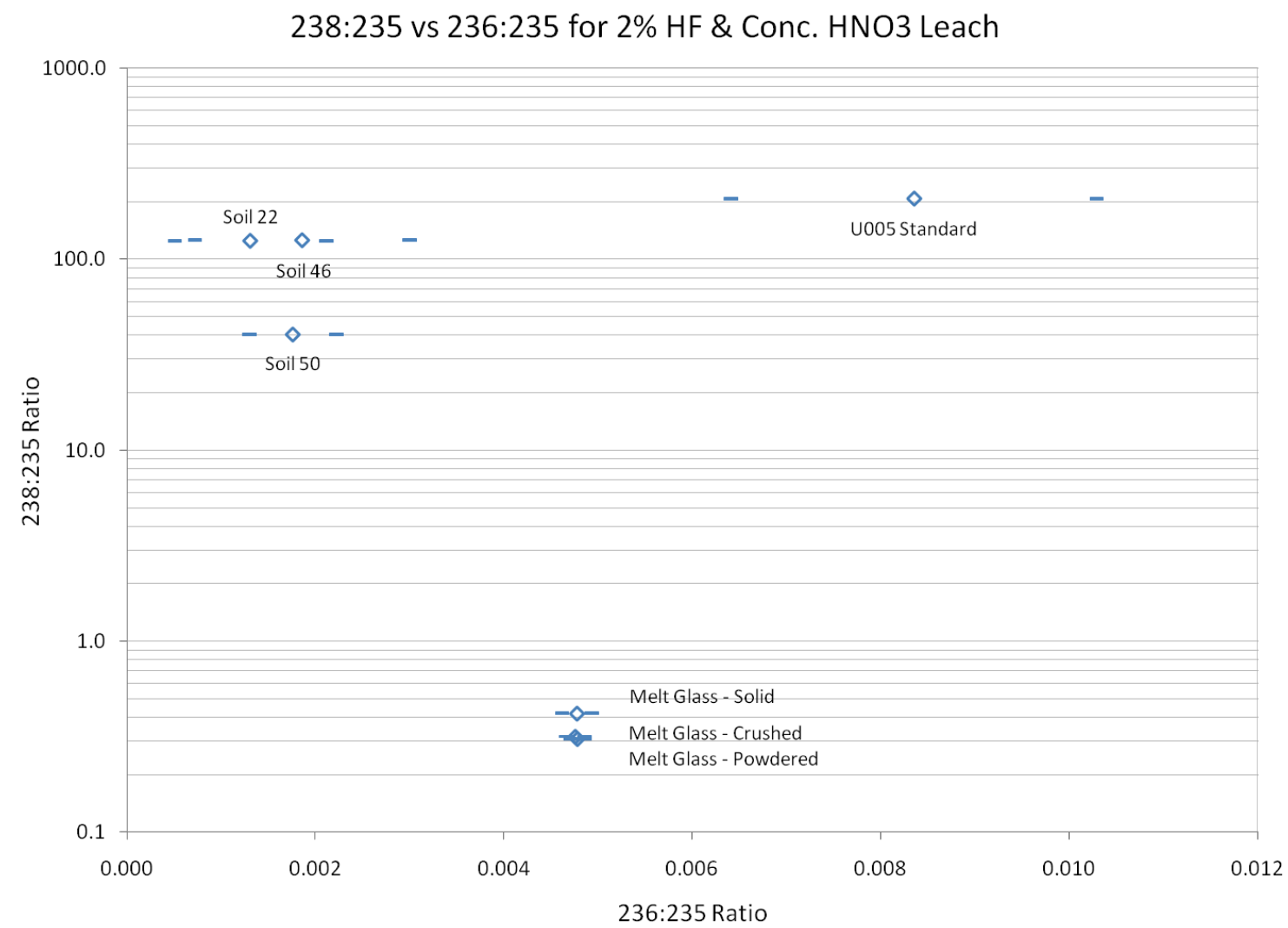

Figure 3: Semi-log ${ }^{238} U /{ }^{235} U$ versus ${ }^{236} U /{ }^{235} U$ mixing curve for three of the soil samples and all of the melt glasses leached by $2 \% \mathrm{HF}$ and concentrated HNO3. The horizontal bars represent the uncertainty in the ${ }^{236} \mathrm{U} /{ }^{235} \mathrm{U}$ values, the ${ }^{238} \mathrm{U} /{ }^{235} \mathrm{U}$ uncertainties are captured within each marker. Errors are $1 \sigma$.

All melt glass leachates yield identical ${ }^{236} U{ }^{235} U$ ratios within $2 \sigma$ errors (Table 2). A significant difference is the total amount of ${ }^{235} \mathrm{U},{ }^{236} \mathrm{U}$ and ${ }^{238} \mathrm{U}$ in the $8 \mathrm{M} \mathrm{HNO}_{3}$ leach treatment relative to the $2 \% \mathrm{HF}$ with concentrated $\mathrm{HNO}_{3}$ treatment, however, resulted in comparatively larger error 
bars in the $8 \mathrm{M} \mathrm{HNO}_{3}$ leachate analyses. Melt glass leached using 2\% $\mathrm{HF}$ with concentrated $\mathrm{HNO}_{3}$ yielded a ${ }^{236} \mathrm{U} /{ }^{235} \mathrm{U}$ ratio of $0.0048 \pm 0.0001$ across 3 samples, showing that the presence of ${ }^{236} \mathrm{U}$ signal is strongly correlated with ${ }^{235} \mathrm{U}$.

Comparison of the total $\mathrm{U}$ signal $\left({ }^{235} \mathrm{U}+{ }^{236} \mathrm{U}+{ }^{238} \mathrm{U}\right)$ produced by the leaching of soils compared to that from the melt glasses, when leached with $2 \% \mathrm{HF}$ with concentrated $\mathrm{HNO}_{3}$, suggests that, although the isotopic compositions differ, the same order of magnitude amount of $U$ is liberated (Table 2). The small ${ }^{236} \mathrm{U}$ signal in the soil samples results in ${ }^{236} \mathrm{U} /{ }^{235} \mathrm{U}$ ratios which approach zero with large uncertainties, are due to the isotopic distribution of $U$ in the soil rather than a byproduct of a diminished total U signal.

A semi-log plot of the ${ }^{238} \mathrm{U} /{ }^{235} \mathrm{U}$ relative to the ${ }^{236} \mathrm{U} /{ }^{235} \mathrm{U}$ ratios for the $2 \% \mathrm{HF}$ with concentrated HNO3 leach samples (Figure 3) shows that the soil and melt glasses form two populations, easily distinguished from each other. This is not surprising, as ${ }^{236} \mathrm{U}$ is nearly absent in natural samples, and tends be present in samples where ${ }^{235} \mathrm{U}$ can have undergone significant neutron capture, such as materials derived from irradiated and/or fissioned uranium. The 'uncontaminated' soils also suggest the presence of a minor, non-natural uranium component, despite having been sampled from the subsurface, away from any known surface fallout plumes. Since the precise point of origin of the NTS soils is not known relative to the melt glass, extrapolating a mixing curve specific to this test shot may not be possible.

\section{Conclusions and Recommendations}

Fast leaching of soils with $8 \mathrm{M} \mathrm{HNO}_{3}$ may be sufficient for a preliminary determination of whether or not an enriched ${ }^{235} \mathrm{U}$ component is present in debris, but does not report the true ${ }^{238} \mathrm{U} /{ }^{235} \mathrm{U}$ value, as given by the full microwave dissolution. Crushed samples do, however, allow more rapid access of the primary uranium component. The times ( 1 hour) and temperatures $\left(\sim 32^{\circ}\right.$ C) explored, however, show that a rapid leaching approach using $8 \mathrm{M} \mathrm{HNO}_{3}$ is not sufficient to determine a reliable preliminary ${ }^{238} \mathrm{U} /{ }^{235} \mathrm{U}$ ratio, regardless of the introduced form of the sample.

The addition of $\mathrm{HF}$ to the leaching procedure, as explored using the $2 \% \mathrm{HF}$ with concentrated $\mathrm{HNO}_{3}$ leach samples, significantly increases the yield of uranium from the sample. These analyses suggest that this approach is significantly enhanced if the sample surface area is increased (crushed) prior to rapid leaching. Measurement of the bulk isotopic composition of the melt glass from a complete dissolution provides a comparison of the 'real' uranium isotopic composition of the fallout, and shows no combination of $2 \% \mathrm{HF}$ with concentrated $\mathrm{HNO}_{3}$ leaching of the crushed and powdered samples from this set of experiments realized these values within errors.

In practical terms, these data suggest that the use of HF is required to access the dominant uranium component in melt glass, and it is recommended that the samples be crushed or powdered to optimize the leaching procedure. Leach periods may need to be extended beyond 1 hour, though these preliminary data suggest that 1 hour is sufficient if a simple crushing precedes the leach step. If a sample of pure melt glass is available, we conservatively predict that sample masses as small as $25 \mathrm{mg}$ are adequate to determine ${ }^{238} \mathrm{U} /{ }^{235} \mathrm{U}$ and ${ }^{236} \mathrm{U} /{ }^{235} \mathrm{U}$ ratios to better than $5 \%$, including all propagated errors, assuming a ${ }^{235} \mathrm{U}$ loading of $10^{16}$ atoms $/ \mathrm{g}$. While not 
providing true ratios, such a measurement would clearly establish the presence of enriched material.

As a proof of concept, these experiments demonstrate that fast leaching and ICP-MS analysis can be a useful tool for the preliminary analysis of actinide isotopic ratios in soils and melt glass. To validate these data and establish operational limits, additional experiments need to be performed. Coupled leaching and complete dissolution experiments on similar samples should be pursued to determine if the isotopic ratios from the leaching process are representative of the isotopic ratios in the soil. The leaching process also should be tested against $\mathrm{Pu}$ and mixed $\mathrm{Pu} / \mathrm{U}$ systems to determine if the dissolution rates of $\mathrm{Pu}$ and $\mathrm{U}$ are different, and if they are, to determine a leaching period and set of reagents sufficient for all actinides of interest. 